\title{
Successful treatment of refractory hepatic lymphorrhea after gastrectomy for early gastric cancer, using surgical ligation and subsequent OK-432 (Picibanil) sclerotherapy
}

\author{
Kouji Tanaka ${ }^{1}$, Yukinari Ohmori ${ }^{1}$, Yasuhiko Mohri ${ }^{1}$, Hitoshi Tonouchi ${ }^{2}$, Mina Suematsu ${ }^{3}$, Yukiko Taguchi ${ }^{3}$, \\ Yukiniko Adachi ${ }^{3}$, and Masato KusunOKI ${ }^{1,2}$ \\ ${ }^{1}$ The Second Department of Surgery, Mie University School of Medicine, 2-174 Edobashi, Tsu, Mie 514-8507, Japan \\ ${ }^{2}$ Department of Innovative Surgery, Mie University School of Medicine, Mie, Japan \\ ${ }^{3}$ The Third Department of Internal Medicine, Mie University School of Medicine, Mie, Japan
}

\begin{abstract}
Postoperative hepatic lymphorrhea is a very rare complication after abdominal surgery. Hepatic lymphorrhea, not containing chyle, involves an internal lymph fistula between the lymphatic channels toward the cisterna chyli and the peritoneal cavity. Over the past 20 years, 17 cases have been reported in Japan. Here, we report a further case, of a patient with successfully treated intractable hepatic lymphorrhea following gastrectomy for early gastric cancer. We review 18 cases, including the present case, with respect to the management of postoperative lymphorrhea refractory to conventional medical treatment.
\end{abstract}

Key words Hepatic lymphorrhea - Gastrectomy · Surgical ligation · OK-432 (Picibanil) sclerotherapy

\section{Introduction}

Chylous ascites following abdominal surgery is a rare complication [1], but it has been reported after various surgical procedures, including abdominal aortic surgery [2], retroperitoneal lymph node dissection [3], esophagectomy [4,5], pancreaticoduodenectomy [6], and gastrectomy [7]. Although there are many reports in the English-language literature describing the diagnosis, causes, and treatment of chylous ascites [8,9], little is known about hepatic lymphorrhea, not containing chyle, following abdominal surgery. To our knowledge, there has not been any report of hepatic lymphorrhea following abdominal surgery in the English-language literature. However, over the past 20 years, 17 cases have been reported in Japan [10-22].

Hepatic lymphorrhea, not containing chyle, involves an internal lymph fistula between the lymphatic channels toward the cisterna chyli and the peritoneal cavity,

Offprint requests to: $\mathrm{M}$. Kusunoki

Received: November 26, 2003 / Accepted: February 16, 2004 resulting from probable lymphatic duct injuries during lymph node dissection for a gastric malignancy. Gastrectomy with lymph node dissection is performed acceptably in most Japanese institutions; however, lymphorrhea is frequently encountered after gastric surgery, although the postoperative lymphatic leakage generally stops spontaneously without treatment. There is, though, little information about a standard treatment for postoperative lymphorrhea, which is highly refractory to any conventional medical treatments such as cessation of oral intake, total parenteral nutrition (TPN) management, diuretic therapy, intravenous reinfusion of ascites, or therapeutic paracentesis.

Here, we present a case of intractable lymphorrhea in a patient who was successfully treated with surgical lymph vessel ligation, and subsequent OK-432 (Picibanil; Chugai Pharmaceutical, Tokyo, Japan) sclerotherapy. Additionally, we review the present case and the 17 previous reports noted above, and discuss management options.

\section{Case report}

A 66-year-old man was referred to our department for medical treatment for refractory ascites. One year before admission, he had undergone, in our department, a total gastrectomy with lymphadenectomy for early gastric cancer. Because preoperative study showed that the tumor had probably invaded to the submucosal layer, we performed extended lymph node dissection, including the regional lymph nodes and additional lymph nodes, along the common hepatic artery. His postoperative course was uneventful. The final, pathological staging was $\mathrm{T} 1$ (SM), N0, H0, P0, M0, stage IA according to the Japanese classification of gastric carcinoma, second edition [23]. He had chronic B-type viral hepatitis, and was non-cirrhotic, but with normal liver function tests. There was no evidence of recurrence on the basis of 


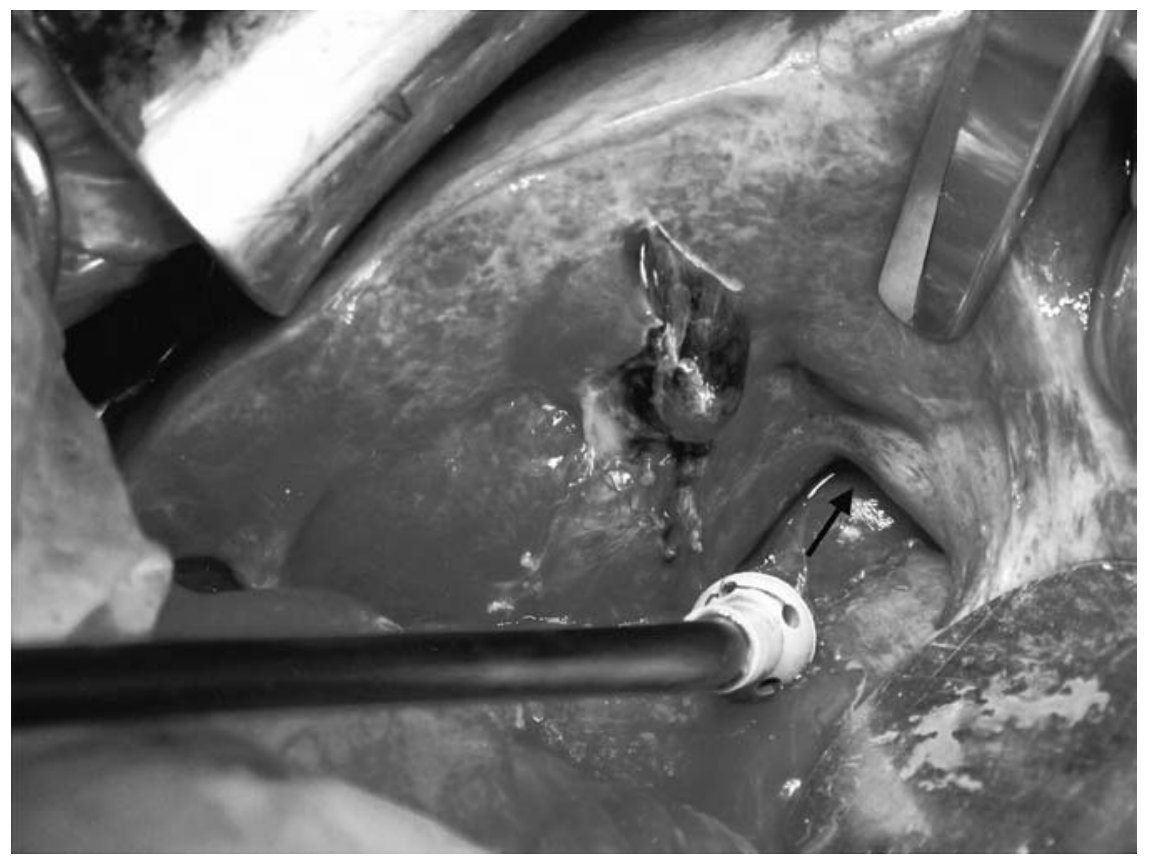

Fig. 1. A few minutes after the injection of patent blue violet solution into the liver bed, a dye-stained lymphatic duct (arrow) was easily identified clinical observations, biological tests, and imaging studies done on an outpatient basis.

About 4 months after the curative surgery for gastric cancer, abdominal distension gradually developed. He was admitted to the Internal Medicine Department at our hospital for the assessment of abdominal distension and liver function. Bilateral pitting edema of the legs and massive ascites was noted. Laboratory tests and imaging studies indicated that the massive ascites may be responsible for postoperative lymphorrea not associated with liver dysfunction due to the chronic B-type viral hepatitis. Finally, fluid analysis obtained from diagnostic paracentesis demonstrated that the ascitic fluid was clear-colored, and he was diagnosed with nonchylous lymphorrhea by biochemical tests of the fluid. Cytological examination of the fluid revealed no evidence of peritoneal cancer recurrence. Total parenteral nutrition (TPN), diuretic therapy, and therapeutic paracentesis were begun. Neither symptomatic relief nor a decrease in abdominal size was achieved despite these therapies being carried out over a 6-month period. Although lymphoscintigraphy did not show an obvious lymphatic leakage point, we decided to perform surgical intervention because the ascites was non-responsive to all the conservative therapies used.

Exploratory laparotomy was performed after medical treatment had been given for over 120 days. There was a large amount of clear ascitic fluid but no evidence of peritoneal recurrence of gastric cancer. To detect the lymphatic channels causing lymphorrhea, we used 2\% patent blue violet dye (Wako Pure Chemical Industries, Osaka, Japan), a dye used for lymphatic mapping. Because the lymphorrhea would probably have been caused by an injury to the lymphatic ducts during lymph node dissection, we injected this solution into the liver bed. The dye-stained lymphatic ducts were easily identified (Fig. 1) and successfully ligated. However, we could not achieve complete resolution of the lymph leak because other lymphatic leaks emerged posterior to the hepatoduodenal ligament. Therefore, fibrin glue was applied to treat minor lymphatic leakages.

The small amount of lymphatic outflow from the drain tube was postoperatively treated with an injection of OK-432 (Picibanil). Repeated sclerotherapeutic sessions (six times in total), using a total dose of $45 \mathrm{KE}$, led to the complete disappearance of the ascites within 67 days. No adverse effects were observed, except for a temporary mild fever and some slight abdominal pain. The patient has continued to do well, without hepatic lymphorrea or cancer recurrence, 6 months after being discharged.

\section{Discussion}

Intraabdominal lymphorrhea, without chylous ascites, occurring after abdominal surgery is a rare complication, resulting from an internal lymph fistula between the lymphatic channels toward the cisterna chyli and the peritoneal cavity. Although small lymph leaks are commonly seen during lymphadenectomy, they rarely cause lymphorrhea because of the abundance of collateral lymphatic channels in the abdominal cavity. In most cases, they remain clinically asymptomatic or unrecognized. Despite the large number of abdominal surgeries that have been performed, little is known about post- 
Table 1. Characteristics of 18 patients with hepatic lymphorrhea after gastric surgery

\begin{tabular}{|c|c|c|c|c|c|c|}
\hline Case no. & Author & $\begin{array}{c}\text { Age/Sex } \\
\text { (years) }\end{array}$ & $\begin{array}{c}\text { Liver disease } \\
\text { (medical history) }\end{array}$ & Diagnosis & Operation & $\begin{array}{l}\text { Onset of lymphorrhea } \\
\text { (postoperative days) }\end{array}$ \\
\hline 1 & Miyagawa, 1983a & $65 / \mathrm{M}$ & HBsAg $(+)$ & GC (advanced stage) & TG & 1 \\
\hline 2 & Nakashima, 1985 [10] & $58 / \mathrm{M}$ & None & GC (advanced stage) & DG & 6 \\
\hline 3 & Nakano, 1987 a & $49 / \mathrm{M}$ & None & GC (advanced stage) & TG & 1 \\
\hline 4 & Kawata, 1989 [11] & $52 / \mathrm{M}$ & Liver cirrhosis & GC (early stage) & DG & 7 \\
\hline 5 & Umehara, 1989 [12] & $59 / \mathrm{M}$ & None & GC (advanced stage) & TG & 8 \\
\hline 6 & Kaneko, 1991 [13] & $44 / \mathrm{M}$ & None & GC (early stage) & DG & 35 \\
\hline 7 & Imai, 1992 [14] & $34 / \mathrm{M}$ & Liver dysfunction & Gastric leiomyosarcoma & TG & 6 \\
\hline 8 & Shimizu, 1992 [15] & $62 / \mathrm{M}$ & Liver cirrhosis & GC (early stage) & DG & 1 \\
\hline 9 & Ota, 1993 [16] & $70 / \mathrm{M}$ & $\mathrm{CH}$ & GC (early stage) & DG & 63 \\
\hline 10 & Mitsuno, 1993 & $42 / \mathrm{M}$ & $\mathrm{CH}$ & GC (early stage) & DG & 5 \\
\hline 11 & Sasaki, 1994 [17] & $54 / \mathrm{M}$ & Liver cirrhosis & GC (early stage) & DG & 7 \\
\hline 12 & Kawahira, 1994 [18] & $58 / \mathrm{M}$ & $\mathrm{CH}$ & GC (advanced stage) & DG & 32 \\
\hline 13 & Matsumoto, 1995 [19] & $44 / \mathrm{M}$ & $\mathrm{CH}$ & GC (advanced stage) & DG & 3 \\
\hline 14 & Tada, 1996 [20] & 79/M & $\mathrm{CH}$ & GC (early stage) & DG & 1 \\
\hline 15 & Tada, 1996 [20] & $57 / \mathrm{M}$ & $\mathrm{CH}$ & GC (early stage) & DG & 1 \\
\hline 16 & Takahata, 1998 [21] & 49/M & $\mathrm{CH}$ & GC (advanced stage) & DG & 1 \\
\hline 17 & Yoshida, 2000 [22] & $55 / \mathrm{M}$ & Liver cirrhosis & GC (advanced stage) & DG & 60 \\
\hline 18 & Present report, 2002 & $66 / \mathrm{M}$ & $\mathrm{CH}$ & GC (early stage) & TG & 120 \\
\hline
\end{tabular}

None, no hepatic disease; $\mathrm{CH}$, chronic hepatitis; GC, gastric cancer; TG, total gastrectomy; DG, distal gastrectomy

${ }^{a}$ Cited in reference 14

Table 2. Therapies for and clinical outcome of hepatic lymphorrhea

\begin{tabular}{|c|c|c|c|}
\hline Case no. & Prior treatment (duration; days) & Treatment & $\begin{array}{l}\text { Time to complete } \\
\text { resolution (days) }\end{array}$ \\
\hline 1 & Medical treatment (183) & Surgical ligation & 13 \\
\hline 2 & Medical treatment (30) & $\begin{array}{l}\text { Surgical ligation }+ \text { antibiotics } \\
\quad+\text { sclerotherapy }\end{array}$ & 30 \\
\hline 3 & Medical treatment (47) & Surgical ligation & 14 \\
\hline 4 & Medical treatment (101) & $\begin{array}{l}\text { Surgical ligation }+ \text { fibrin glue } \\
+ \text { sclerotherapy }\end{array}$ & 37 \\
\hline 5 & Medical treatment (97) & Surgical ligation & 28 \\
\hline 6 & Medical treatment (63) & Surgical ligation + PV shunt & 30 \\
\hline 7 & $\begin{array}{l}\text { Medical treatment, sclerotherapy, } \\
\text { PV shunt (111) }\end{array}$ & Reoperation + antibiotics + sclerotherapy & 7 \\
\hline 8 & $\begin{array}{l}\text { Medical treatment, sclerotherapy, } \\
\text { PV shunt (630) }\end{array}$ & Surgical ligation & 30 \\
\hline 9 & Medical treatment (60) & Surgical ligation + fibrin glue & 50 \\
\hline 10 & Medical treatment (105) & PV shunt & $?$ \\
\hline 11 & Medical treatment (60) & OK-432 sclerotheraoy (50 KE, 4 times) & 150 \\
\hline 12 & Medical treatment, PV shunt (238) & $\begin{array}{l}\text { Surgical ligation }+ \text { fibrin glue }+ \text { OK- } 432 \\
\text { sclerotherapy }\end{array}$ & 10 \\
\hline 13 & $\begin{array}{l}\text { Medical treatment, surgical ligation, } \\
\text { PV shunt (288) }\end{array}$ & Re-re-surgical ligation + fibrin glue & 14 \\
\hline 14 & Medical treatment (34) & OK-432 sclerotherapy (75 KE, 6 times) & 54 \\
\hline 15 & Medical treatment (25) & OK-432 sclerotherapy ( $25 \mathrm{KE}, 3$ times) & 47 \\
\hline 16 & Medical treatment (44) & $\begin{array}{l}\text { Surgical ligation }+ \text { fibrin glue }+ \text { OK- } 432 \\
\text { sclerotherapy }\end{array}$ & 12 \\
\hline 17 & Medical treatment (120) & OK-432 sclerotherapy (20 KE, 2 times) & 43 \\
\hline 18 & Medical treatment (180) & $\begin{array}{l}\text { Surgical ligation }+ \text { fibrin glue }+ \text { OK- } 432 \\
\text { sclerotherapy }\end{array}$ & 67 \\
\hline
\end{tabular}

Medical treatment: total parenteral nutrition (TPN), diuretics, paracentesis, and/or reinfusion

$\mathrm{PV}$, peritoneo-venous

${ }^{a}$ Duration from the beginning of treatment to complete disappearance of lymphorrhea

operative hepatic lymphorrhea. To our knowledge, there has not been any report of hepatic lymphorrhea following abdominal surgery in the English-language medical literature, although there are many reports about chylous ascites after various abdominal surgeries [1-7]. To clarify the clinical features, we reviewed the 17 cases reported in the Japanese medical literature plus the present case (Tables 1 and 2). 
Table 3. Comparison between treatments and variables, including clinical outcome

\begin{tabular}{|c|c|c|c|c|}
\hline \multicolumn{2}{|l|}{ Variable } & \multirow{2}{*}{$\begin{array}{l}\text { A. Surgical treatment } \\
\qquad(n=14) \\
2\end{array}$} & \multirow{2}{*}{$\begin{array}{c}\text { B. Sclerotherapy alone } \\
(n=4)\end{array}$} & \multirow[t]{2}{*}{$P$ value } \\
\hline 1. Medical history & Liver cirrhosis & & & \\
\hline & Chronic hepatitis & 7 & 2 & 0.53 \\
\hline \multirow{2}{*}{ 2. Gastric cancer } & Advanced stage & 7 & 1 & \\
\hline & Early stage & 6 & 3 & 0.58 \\
\hline \multirow{2}{*}{ 3. Operation } & Total gastrectomy & 5 & 0 & \\
\hline & Distal gastrectomy & 9 & 4 & 0.28 \\
\hline \multicolumn{2}{|c|}{$\begin{array}{l}\text { 4. Onset of postoperative lymphorrhea } \\
\text { (postoperative days) }\end{array}$} & $21 \pm 34$ & $18 \pm 28$ & 0.88 \\
\hline \multirow{2}{*}{\multicolumn{2}{|c|}{$\begin{array}{l}\text { 5. Duration of prior treatment (days) } \\
\text { 6. Time to complete resolution (davs) }\end{array}$}} & $156 \pm 157$ & $60 \pm 43$ & 0.25 \\
\hline & & $23 \pm 13$ & $74 \pm 51$ & $<0.01$ \\
\hline
\end{tabular}

A, Direct surgical ligation was performed; if required, fibrin glue sprinkle, supportive sclerotherapy, and PV shunting were added

B, Paracenteses, followed by intraperitoneal OK-432 injection without any surgical treatment

Data values are given as means $\pm \mathrm{SD}$, or as numbers

${ }^{a}$ Fisher's exact test or Mann-Whitney U-test

The patients were 13 men and 5 women, ranging in age from 34 to 79 years (mean, 55 years). All patients were diagnosed as having a gastric malignancy, including gastric cancer (advanced stage, 8 ; early stage, 9 ) and gastric leiomyosarcoma (1), and they underwent either distal gastrectomy (13) or total gastrectomy (5). Thirteen $(72 \%)$ had a medical history of liver disease: laboratory liver dysfunction (1), chronic hepatitis (8), and liver cirrhosis (4). The mean time from gastric surgery to the onset of lymphorrhea was 20 days (range, 1 to 120 days). After the diagnosis of postoperative lymphorrhea was established, all patients were treated conventionally by diet, TPN, diuretics, therapeutic paracentesis, and/or intravenous reinfusion of ascites. However, none of the patients responded to any of these conservative therapies after durations of treatments ranging from 25 to 630 days (mean, 134 days).

Although there was no significant association between the duration of medical treatment and the presence (or degree) of liver disease, these observations suggest that such intractable lymphorrhea may be caused not only by injury to the lymphatic ducts during lymph node dissection but also by increased lymph flow and lymph production secondary to chronic liver disease.

Table 2 shows that various types of therapies for refractory lymphorrhea have been used, and that the therapeutic strategies pursued have not been uniform. Kaas et al. [1] indicated that no relaparotomies for ligation of lymph fistula were necessary because complete resolution was achieved by conservative management or peritonea-venous (PV) shunt insertion. In contrast, Haukaas et al. [3] have reported that direct surgical closure is a valid treatment option in patients with persistent chylous fistula after retroperitoneal lymph node dissection.

After conventional medical treatment, various regimens were used to treat the intractable hepatic lymph- orrhea (Table 2). These regimens were divided into two groups. In group A (surgical treatment), direct surgical ligation was performed, if required, and fibrin glue sprinkle, supportive sclerotherapy, and PV shunting were added. In group B (sclerotherapy alone), paracentesis was followed by an intraperitoneal OK-432 injection without any surgical treatment.

Most importantly, as shown in Table 3, the time to complete resolution in group A was significantly shorter than that in group B $(P<0.01)$. The most effective therapy for intractable lymphorrhea appears to have been surgical ligation of lymph fistula with supportive sclerotherapy and/or fibrin glue sprinkle. Even if the preoperative imaging study does not show an obvious leakage point, surgical ligation should be performed, together with intraoperative injection of dye such as patent blue violet [24].

Peritoneo-venous shunting has become a less common technique recently, because of the high associated morbidity, such obstruction, vascular thrombosis, infections, sepsis, and disseminated intravascular coagulopathy (DIC) [8,9]. Table 2 also shows that almost all patients with a PV shunt insertion underwent additional surgery to treat subsequent complications. Although the insertion of a PV shunt is recommended as one of the management techniques for refractory chylous ascites $[1,25]$, the results indicate that PV shunt insertion should be avoided if possible, because of the resulting longer duration of treatment.

In conclusion, hepatic lymphorrhea after gastrectomy with lymph node dissection was generally refractory to conventional medical treatment, and often occurred in patients with liver disease. The analysis of data reported in 18 cases suggests that early surgical exploration with direct ligation of leaking lymphatics may be the first choice of treatment in the management of intractable lymphorrhea and that the timing of surgical intervention may also be important. In the face of failing con- 
ventional medical treatments for refractory lymphorrhea, a surgeon should try to perform direct ligation of any lymph leaks as soon as possible, before the patient's general condition deteriorates further.

\section{References}

1. Kaas R, Rustman LD, Zoetmulder FA. Chylous ascites after oncological abdominal surgery: incidence and treatment. Eur J Surg Oncol 2001;27:187-9.

2. Pabst TS 3rd, McIntyre KE, Schilling JD, Hunter GC, Bernhard VM. Management of chyloperitoneum after abdominal aortic surgery (review). Am J Surg 1993;166:194-8.

3. Haukaas SA, Daehlin L, Ulvik NM, Hostmark J, Nordli D. Surgical management of chylous fistula after retroperitoneal lymph node dissection (review). Scand J Urol Nephrol 1999; 33:71-2.

4. Guillem P, Billeret V, Houcke ML, Triboulet JP. Successful management of post-esophagectomy chylothorax/chyloperitoneum by etilefrine. Dis Esophagus 1999;12:155-6.

5. Fujiwara Y, Nakagawa K, Kusunoki M, Hatada T, Yamamura T, Utsunomiya J. Massive pleural effusion and ascites resulting from esophagectomy with extensive lymphadenectomy for cancer of the abdominal esophagus. Hepatogastroenterology 1999;46:290-4.

6. Kollmar O, Schilling MK, Buchler MW. Treatment of chyloperitoneum after extended lymphatic dissection during duodenopancreatectomy (review). Int J Pancreatol 2000;27:83-7.

7. Rajasekar A, Ravi NR, Diggory RT. Chylous ascites: a rare complication of radical gastrectomy. Int J Clin Pract 2000;54:201-3.

8. Laterre PF, Dugernier T, Reynaert MS. Chylous ascites: diagnosis, causes and treatment (review). Acta Gastroenterol Belg 2000; 63:260-3.

9. Aalami OO, Allen DB, Organ CH Jr. Chylous ascites: a collective review (review). Surgery 2000;128:761-78.

10. Nakashima R, Fujita T, Shirasaki O, Hokari I, Karaki Y, Fujimaki M. Severe hepatic ascites following distal subtotal gastrectomy; report of a case (in Japanese with English abstract). Rinsho Geka (J Clin Surg) 1985;40:689-92.

11. Kawata N, Morita H, Matsumoto K, Iwahashi K, Tsunekawa K. A case of hepatic lymphorrhea after radical gastric cancer operation with liver cirrhosis (in Japanese with English abstract). Rinpa Gaku (Jpn J Lymphol) 1989;12:53-7.

12. Umehara $Y$, Miyahara $T$, Yoshida $M$, Oba N, Gotou H, Harada Y. A case report of intractable hepatic lymphorrhea following radical gastrectomy for gastric cancer (in Japanese with English abstract). Nihon Syokakigeka Gakkaizasshi (Jpn J Gastroenterol Surg) 1989;22:2441-4.

13. Kaneko $\mathrm{Y}$, Tanaka M, Hayashi H, Ietsugu K, Iwagami S, Kiyokawa $\mathrm{H}$, et al. A case report of intractable massive ascites (hepatic lymphorrhea) following radical gastrectomy for early gastric cancer (in Japanese with English abstract). Syokakigeka (Gastroenterol Surg) 1991;14:905-11.
14. Imai S, Suda H, Sibuya T, Sibuya J, Shouji T. A case report of intractable hepatic lymphorrhea following radical operation for gastric leiomyosarcoma (in Japanese with English abstract) Nihon Rinsyogeka Gakkaizasshi (J Jpn Surg Assoc) 1992;53:1182-6.

15. Shimizu Y, Tanaka T, Nakae A, Itoi H, Matui S, Nagashima K. A case of intractable massive ascites (hepatic lymphorrhea) following radical gastrectomy for early gastric cancer (in Japanese with English abstract). Kyoto Furitsu Ikadaigaku Zasshi. (J Kyoto Prefectural University of Medicine) 1992;101:175-80.

16. Ota H, Miyazawa T, Inaba H, Ueda N, Maeura Y, Matsunaga S, et al. A case report of intractable ascites due to hepatic lymphorrhea from hepatoduodenal ligament after radical gastrectomy for gastric cancer (in Japanese with English abstract). Nihon Syokakigeka Gakkaizasshi (Jpn J Gastroenterol Surg) 1993; 26:1115-9.

17. Sasaki H, Nakagawa K, Shiiki S, Yamashita Y, Yumura M, Kodani J. An effective treatment by intraperitoneal OK-432 for intractable hepatic lymphorrhea after radical gastrectomy for early gastric cancer with liver cirrhosis. A case report (in Japanese with English abstract) Nihon Rinsyogeka Gakkaizasshi (J Jpn Surg Assoc) 1994;55:159-63.

18. Kawahira Y, Nakao K, Nakahara M, Hamaji M, Ogino N, Miyazaki S. A case of intractable hepatic lymphorrhea after gastrectomy for gastric cancer (in Japanese with English abstract). Nihon Syokakigeka Gakkaizasshi (Jpn J Gastroenterol Surg) 1994;27:117-20.

19. Matsumoto H, Nomura S, Washio K, Fujioka M, Kobashi Y, Usui $\mathrm{Y}$, et al. A case of intractable hepatic lymphorrhea following radical gastrectomy for a gastric cancer (in Japanese with English abstract) Nihon Rinsyogeka Gakkaizasshi (J Jpn Surg Assoc) 1995;56:1918-22.

20. Tada I, Arita T, Abe T, Yashuda K, Kano T, Kaketani K, et al. Intractable massive ascites following radical gastrectomy for an early gastric cancer - two case reports (in Japanese with English abstract). Nihon Rinsyogeka Gakkaizasshi (J Jpn Surg Assoc) 1996;57:451-6.

21. Takahata H, Obino K, Nakano H. A case report of intractable hepatic lymphorrhea following radical gastrectomy for gastric cancer (in Japanese with English abstract). Rinsho Geka (J Clin Surg) 1998;53:499-503.

22. Yoshida M, Matsuyama H. A case of an effective treatment with intraperitoneal OK-432 administration for intractable hepatic lymphorrhea after radical gastrectomy for gastric cancer with liver cirrhosis (in Japanese with English abstract). Tokyo Joshi Ikadaigaku Zasshi (J Tokyo Women's Medical University School of Medicine) 2000;70:21-4.

23. Japanese Research Society for Gastric Cancer. Japanese classification of gastric carcinoma. 2nd English ed. Tokyo: Kanehara; 1997.

24. Setoyama M, Shimada H, Kanzaki T. Successful mapping of lymphorrhea using patent blue dye after lymph node dissection for malignant melanoma. J Dermatol 2000;27:407-8.

25. Haug ES, Saether OD, Odegaard A, Johnsen G, Myhre HO. Chylous complications after abdominal aortic surgery. Int Angiol 1998;17:244-7. 